\title{
Aggressive recurrence of early breast invasive ductal carcinoma with gastric metastasis during adjuvant hormonal therapy
}

\author{
Yasuyuki Shigematsu ${ }^{* 1}$, Kazuhiro Araki $^{2}$, Rie Horii ${ }^{3}$, Futoshi Akiyama ${ }^{3}$, Shunji Takahashi ${ }^{1}$, Shinji Ohno $^{2}$, Yoshinori \\ Itoh $^{2}$ \\ ${ }^{1}$ Division of General Oncology, The Cancer Institute Hospital, Japanese Foundation of Cancer Research, 3-8-31 Ariake, Koto, \\ Tokyo, Japan \\ ${ }^{2}$ Division of Breast Oncology Center, The Cancer Institute Hospital, Japanese Foundation of Cancer Research, 3-8-31 Ariake, \\ Koto, Tokyo, Japan \\ ${ }^{3}$ Division of Pathology, The Cancer Institute Hospital, Japanese Foundation of Cancer Research, 3-8-31 Ariake, Koto, Tokyo, \\ Japan
}

Received: December 1, 2015

Accepted: December 27, 2015

Online Published: January 14, 2016

DOI: $10.5430 /$ crcp.v3n1p55

URL: http://dx.doi.org/10.5430/crcp.v3n1p55

\begin{abstract}
Introduction: Gastric metastasis of breast invasive ductal carcinoma is rare. We present a case of a patient developing aggressive recurrence of early breast invasive ductal carcinoma with gastric metastasis in the third year of adjuvant hormonal therapy. A rarely observed increase in human epidermal growth factor receptor 2 (HER2) overexpression was also observed at the recurrent metastatic sites, and this situation strongly influenced therapeutic management.

Case presentation: A 49-year-old Japanese female with prolonged back pain was examined by abdominal ultrasound to eliminate the possibility of abdominal malignancy; she was found to have multiple tumors in the liver. Contrast-enhanced computed tomographic (CT) imaging was performed for thorough examination, revealing multiple tumors in abdominal lymph nodes and in the lungs in addition to the liver. An integrated positron emission tomographic CT scan showed metabolically active foci distributed throughout the body, including the thoracic and lumbar vertebrae, para-aortic lymph nodes, liver, and stomach. At the age of 46, the patient had undergone a lumpectomy without axillary lymph node dissection for early breast invasive ductal carcinoma (pT1N0M0 Stage I), and the cancer was positive for both estrogen and progesterone receptors while not overexpressing HER2. Currently, however, biopsies from gastric and liver tumors showed adenocarcinoma with histological and immunohistochemical properties similar to those of the previous breast invasive ductal carcinoma, indicating metastatic breast cancer. Interestingly, HER2 was overexpressed in the metastatic foci, and the difference in expression status influenced the choice of treatment.

Conclusions: Aggressive recurrence of early breast invasive ductal carcinoma with gastric metastasis is rare. Furthermore, HER2 expression status differed between primary and metastatic foci, and reassessment of expression status was helpful for informing decisions on optimal treatment strategy.
\end{abstract}

Key Words: Breast invasive ductal carcinoma, Gastric metastasis, Human epidermal growth factor receptor 2

\footnotetext{
*Correspondence: Yasuyuki Shigematsu; Email: yasuyuki.shigematsu@jfcr.or.jp; Address: Division of General Oncology, The Cancer Institute Hospital, Japanese Foundation of Cancer Research, 3-8-31 Ariake, Koto, Tokyo 135-8550, Japan.
} 


\section{INTRODUCTION}

The recurrence rate of early luminal-type breast cancer undergoing breast-conserving surgery, radiotherapy, and adjuvant hormonal therapy is less than five percent. ${ }^{[1]}$ In cases of recurrence, gastric metastasis is relatively infrequent. ${ }^{[2]} \mathrm{In}$ vasive lobular carcinoma is the most common histological type of breast cancer with gastric metastasis; however, cases of invasive ductal carcinoma with such a presentation are extremely rare. ${ }^{[3,4]}$

We experienced a case of a patient who developed recurrence with gastric metastasis during adjuvant hormonal therapy after breast-conserving surgery and post-operative radiotherapy for early breast invasive ductal carcinoma. Interestingly, in this case, a difference in human epidermal growth factor receptor 2 (HER2) expression status, which has been successfully targeted in breast cancer treatment, was observed between primary and metastatic sites; such differences in expression status are otherwise considered rare. ${ }^{[5-7]}$ Here we present this rare case of breast cancer with gastric metastasis along with a discussion of the diagnosis and treatment strategies.

\section{Case presentation}

A 49-year-old Japanese female with prolonged back pain was examined by abdominal ultrasound to eliminate the possibility of abdominal malignancy and was found to have multiple tumors in the liver. Contrast-enhanced computed tomographic (CT) imaging performed for thorough examination revealed the existence of multiple tumors in abdominal lymph nodes and in the lungs as well. She was referred to our hospital for a workup and treatment of the tumors with a provisional diagnosis of gastrointestinal malignancy. Her past medical history revealed that she underwent lumpectomy without axillary lymph node dissection for early breast invasive ductal carcinoma (pT: $7 \mathrm{~mm} \times 6 \mathrm{~mm}$, pNO, Stage I according to the $7^{\text {th }}$ edition of TNM classification) at the age of 46. The carcinoma was positive for both estrogen receptors $(\mathrm{ER})$ and progesterone receptors $(\mathrm{PgR})$ and did not overexpress HER2. A total of $60 \mathrm{~Gy}$ of external beam irradiation therapy (50 Gy for the remaining breast and a supplemental 10 Gy for the surgical area) was administered to her residual mammary gland. Next, endocrine therapy with $20 \mathrm{mg}$ of daily tamoxifen was initiated as an adjuvant hormonal therapy, and it was planned to continue for five years. During the adjuvant therapy, she had been followed up every six months with repeated physical examination and screening for tumor markers, such as CEA and CA15-3.

On her current visit, the breast cancer tumor markers CEA and CA15-3 were markedly elevated to $1,064 \mathrm{U} / \mathrm{ml}$ and $631 \mathrm{ng} / \mathrm{ml}$, respectively. However, breast palpation did not provide any relevant findings. In a differential diagnosis, we considered the possibility of breast cancer recurrence in addition to the gastrointestinal malignancy. An integrated positron emission tomographic (PET)-CT scan revealed metabolically active foci distributed throughout the body, including the thoracic and lumbar vertebrae, paraaortic lymph nodes, liver, and stomach (see Figure 1).

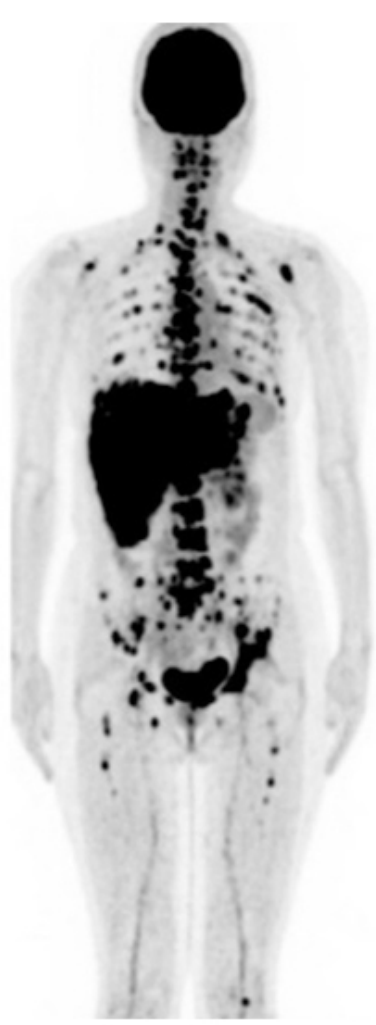

Figure 1. PET-CT fusion image of the entire body Fludeoxyglucose uptake was observed throughout the body, including liver, vertebral bones, and stomach, which was suggestive of metastasis.

Gastrofiberscopic examination revealed multiple erosions in the greater curvature and angular notch of the stomach (see Figure 2); meanwhile, colonoscopic examination showed no abnormalities.

Tumor biopsies from the stomach and liver showed adenocarcinoma, and the histology and immunohistochemistry of E-cadherin, GATA3 (GATA-binding protein 3 to DNA sequence), mammaglobin, MUC5AC, and MUC6 were similar to those of the previous primary breast cancer (see Figure 3). These results suggested that the liver and gastric tumors were in fact metastasized breast cancer. E-cadherin expression was observed in the primary and metastatic tumor cells, and the finding was compatible with the ductal carcinoma. 


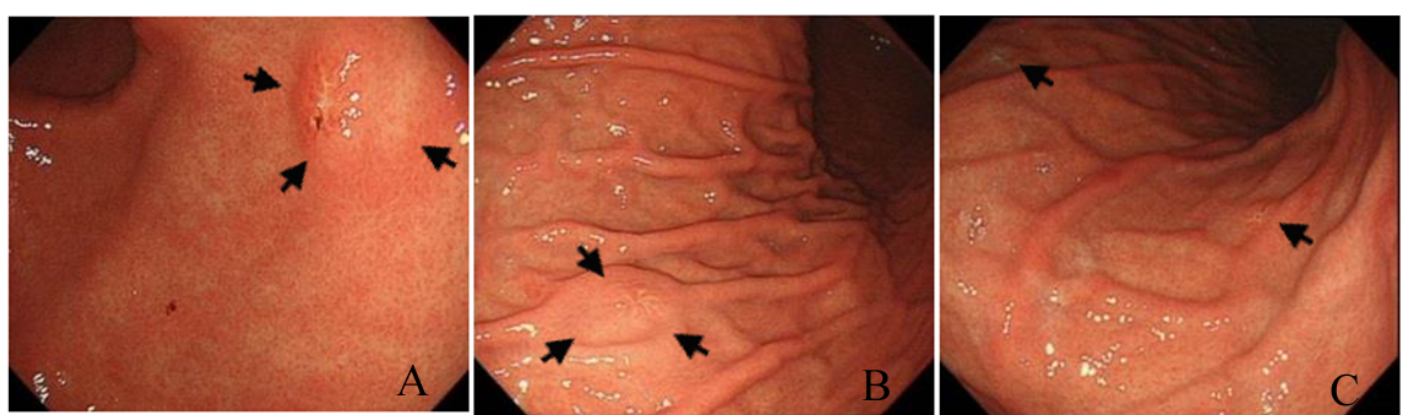

Figure 2. Findings of the gastrofiberscopy Gastrofiberscopy revealed tumors with erosion in (A) the posterior wall of the angular region, (B) the greater curvature of the gastric body, and $(C)$ the greater curvature of the angular region. Arrows indicate a tumor.

The metastatic foci showed the expression of ER and lacked that of PgR. Moreover, HER2 was overexpressed in the metastatic foci. The serum level of the extracellular domain of the HER2 oncoprotein (ECD-HER2) had also increased to $2,510 \mathrm{ng} / \mathrm{ml}$.

Combination chemotherapy including pertuzumab, trastuzumab, and docetaxel was considered as a first-line treatment for metastatic HER2-positive breast cancer. The laboratory data showed elevated levels of aspartate aminotransferase (AST; $356 \mathrm{U} / \mathrm{L}$ ) and alanine aminotransferase (ALT; 152U/L), indicating severe liver damage due to the massive liver metastasis. We speculated that docetaxel was unsafe for use because of the risk of exacerbation of liver damage due to potential adverse events during the treatment course. Thus, we planned to administer only pertuzumab $(840 \mathrm{mg} /$ body initially, with subsequent doses of $420 \mathrm{mg} /$ body every three weeks) and trastuzumab $(6 \mathrm{mg} /$ body initially, with subsequent doses of $4 \mathrm{mg} /$ body every three weeks) until recovery of the liver damage. After the first cycle of the chemotherapy, the ECD-HER2 level decreased markedly to $602 \mathrm{ng} / \mathrm{ml}$, and CEA and CA15-3 also slightly decreased to 2,506.7 U/ml and 997.2 $\mathrm{ng} / \mathrm{ml}$, respectively. However, an evaluation after two cycles of chemotherapy showed that ECD-HER2, CEA, and CA15-3 had increased to 2,010 $\mathrm{ng} / \mathrm{ml}, 2,734.8 \mathrm{U} / \mathrm{ml}$, and $2,940.2 \mathrm{ng} / \mathrm{ml}$, without significant changes in the levels of AST and ALT. Abdominal ultrasound demonstrated marginal increase in the size of the liver tumors. Therefore, we switched to paclitaxel $\left(80 \mathrm{mg} / \mathrm{m}^{2}\right.$, weekly) and trastuzumab $(4 \mathrm{mg} / \mathrm{kg}$ as an initial dose, and subsequent doses of $2 \mathrm{mg} / \mathrm{kg}$ weekly) treatment. The combination chemotherapy successfully controlled the disease (see Figure 4); the patient maintained a good performance status on outpatient chemotherapy.

\section{Discussion}

The recurrence rate of luminal early breast cancer during adjuvant hormonal therapy within five years is less than five Published by Sciedu Press percent. ${ }^{[1]}$ Gastric metastasis has been recognized in only $0.3 \%$ of patients with generalized breast cancer ${ }^{[8]}$ Moreover, in cases of gastric metastasis, lobular carcinoma appears predominant, whereas ductal carcinoma is rare. ${ }^{[9]}$ Gastric metastasis is considered to develop only several years after the initial treatment of breast cancer. ${ }^{[10,11]}$ In the current case, aggressive recurrence of early breast invasive ductal carcinoma with metastasis to the stomach had developed in the third year of adjuvant hormonal therapy. To our knowledge, this is the first report showing recurrence with gastric metastasis of early breast invasive ductal carcinoma within the first three years following surgery.

Diagnosis of gastric metastasis of breast cancer is challenging. Gastric symptoms due to the metastasis are non-specific and may include dyspepsia, anorexia, and epigastric pain; ${ }^{[11]}$ moreover, radiological and endoscopic findings are often indistinguishable from those of primary gastric cancer and non-Hodgkin's lymphoma. ${ }^{[8,12]}$ The lesion is often limited to the submucosa of the stomach, and endoscopic evaluation may be normal in about $50 \%$ of the cases. ${ }^{[13]}$ To be able to distinguish between gastric metastasis of breast cancer and primary gastric cancer, pathological and immunohistochemical analysis is recommended. ${ }^{[14]}$ Histological features should be compared with those of primary breast cancer to confirm the diagnosis. GATA3 expression is most frequently observed in breast and urothelial carcinomas, and $91 \%$ of breast invasive ductal carcinomas exhibit GATA3 expression as evidenced by immunohistochemical analysis. ${ }^{[15]}$ Mammaglobin expression is observed specifically in breast epithelial cells and is reported to be found in $81 \%$ of breast cancer. ${ }^{[16]}$ On the other hand, MUC5AC and MUC6 expression is observed in gastric foveolar cells and glandular cells, respectively, and also occurs in gastric cancer at rates of $67.5 \%$ and $44.9 \%$, respectively, ${ }^{[17]}$ but not in breast cancer. ${ }^{[18]}$ Thus, these differences in expression patterns are useful to distinguish between primary gastric cancer and metastasis of the breast cancer. 
Figure 3. Histological and immunohistochemical analysis of the surgical breast specimen and liver and gastric tumor biopsies

In the breast, invasive ductal carcinoma exhibited E-cadherin and GATA3 expression, and mammaglobin-positive cells were also present. In the liver, tumor cells exhibited E-cadherin and GATA3 expression in the absence of mammaglobin, MUC5AC, and MUC6 expression. In the stomach, tumor cells (indicated by arrows) exhibited E-cadherin and GATA3 and mammaglobin expression in the absence of MUC5AC and MUC6 expression. Although ER positive cells were observed in the breast tumor and the metastatic foci, $P g R$ positive cells were only observed in the breast tumor. The HER 2 expression level in the metastatic foci increased compared to the breast tumor. HE, hematoxylin and eosin stain; original magnification $(\times 100)$.

HER2 expression status in breast cancers may change with tumor progression. The discordance rate of the expression status between primary and recurrent foci was reported in $14.5 \%$ of the cases, ${ }^{[19]}$ and shifting from HER2 negativity to HER2 positivity has been observed in $5 \%$ of the cases. ${ }^{[20]}$ The exact mechanism underlying this discordance has not been studied in detail; it is possible that the change may be induced by chemotherapy. ${ }^{[21,22]}$ However, in our case, the patient received only hormonal therapy as adjuvant treatment,

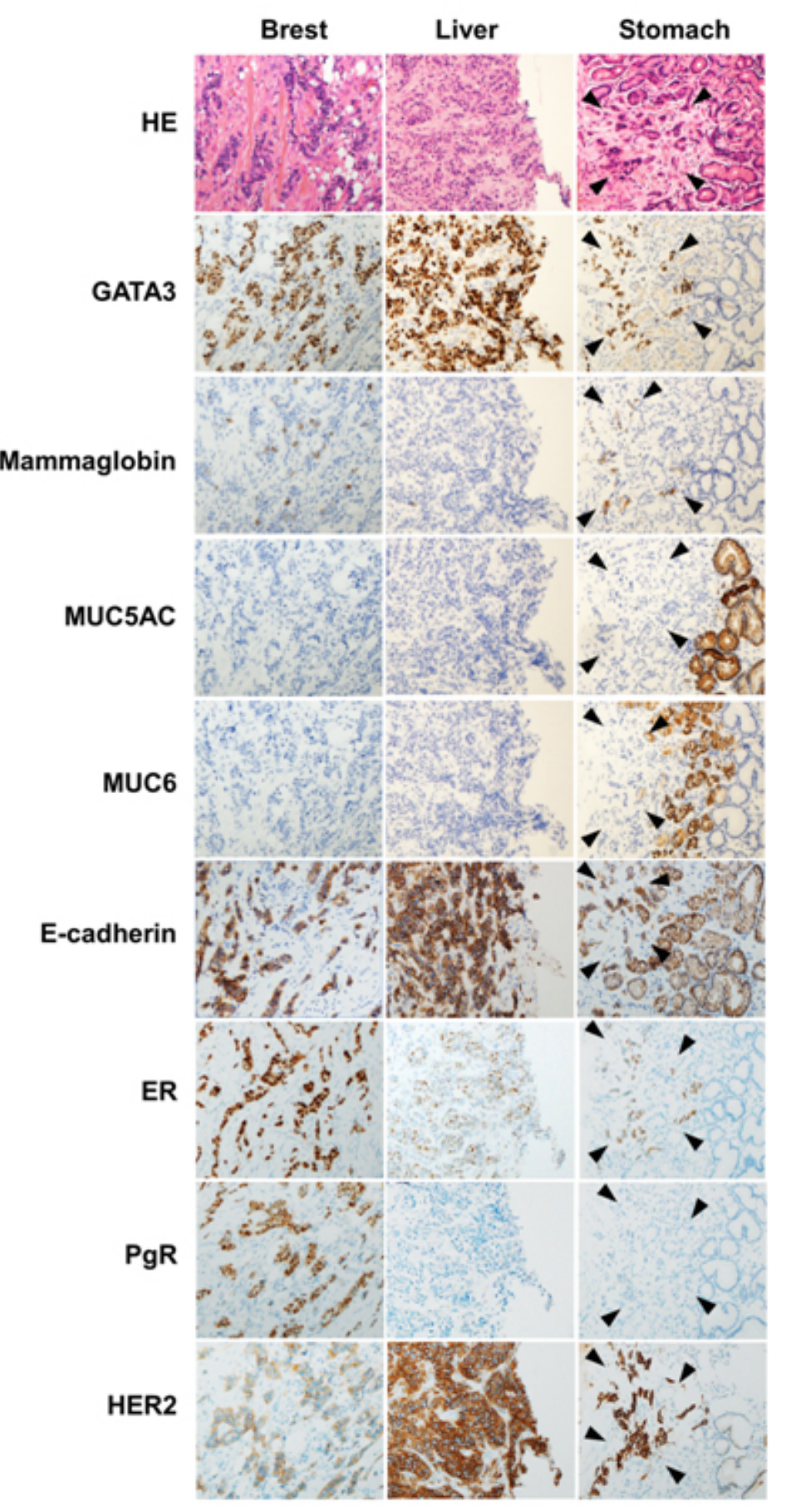

and she had never received chemotherapy at the time when the discordance was observed. Not only the expression status of HER2 but also that of estrogen and progesterone receptors may change. ${ }^{[20]}$ Knowledge on expression status is essential to make an informed decision on the treatment policies and to ensure selection of the best possible targeted therapy. Therefore, biopsy analysis of recurrent or advanced-stage cancer to identify potential changes in hormone receptor and HER2 expression status is considered reasonable. 


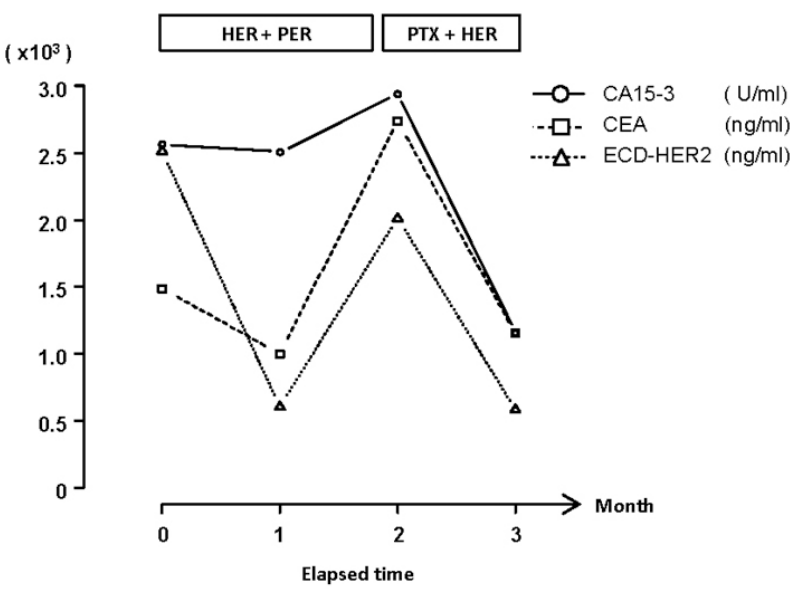

Figure 4. Transition of the levels of tumor markers in the first three months after initiation of chemotherapy for metastatic breast cancer

ECD-HER2 levels changed according to the response to the chemotherapy, and the change in ECD-HER2 level was quite similar to that observed for other tumor markers, including CA15-3 and CEA. HER, herceptin; PER, pertuzumab; PTX, paclitaxel

For patients with HER2-positive metastatic breast cancer, HER2-directed agents should be a component of the treatment. On the other hand, those with HER2-negative metastatic breast cancer should not use them. The combination of pertuzumab plus trastuzumab, which are anti-HER2 humanized monoclonal antibodies, with docetaxel is used as first-line treatment for HER2-positive metastatic breast cancer. ${ }^{[23]}$ In the present case, docetaxel was regarded not to be an option due to metastasis-induced severe liver damage. To evaluate the response to the chemotherapy, we monitored the patient's ECD-HER2 levels. ECD-HER2 is considered useful for predicting the response to the HER2-targeted therapy, and serial changes in ECD-HER2 levels have been reported to parallel the clinical course of the disease. ${ }^{[24-26]}$ In our patient, the ECD-HER2 trend was similar to that of other tumor markers, and the increase in ECD-HER2 levels was consistent with the progression of the disease.

In conclusion, we experienced a rare case of aggressive recurrence of early breast ductal carcinoma with gastric metastasis already in the third year after operation. Furthermore, HER2 expression status differed between primary and recurrent metastatic foci, and reassessment of expression status was helpful to decide on the optimal treatment strategy.

\section{ACKNOWLEDGEMENTS}

The authors thank Dr. Ippei Fukada and Dr. Kokoro Kobayashi for helpful discussions of the manuscript.

\section{REFERENCES}

[1] Darby S, McGale P, Correa C, et al. Effect of radiotherapy after breast-conserving surgery on 10-year recurrence and 15-year breast cancer death: meta-analysis of individual patient data for 10,801 women in 17 randomised trials. Lancet. 2011; 378: 1707-16. http://dx.doi.org/10.1016/S0140-6736(11)61629-2

[2] Taal BG, den Hartog Jager FC, Steinmetz R, et al. The spectrum of gastrointestinal metastases of breast carcinoma: I. Stomach. Gastrointest Endosc. 1992; 38: 130-5. http://dx.doi .org/10.1016 /S0016-5107 (92) 70377-0

[3] Borst MJ, Ingold JA. Metastatic patterns of invasive lobular versus invasive ductal carcinoma of the breast. Surgery. 1993; 114: 637-41; discussion 641-2. PMid: 8211676.

[4] Harris M, Howell A, Chrissohou M, et al. A comparison of the metastatic pattern of infiltrating lobular carcinoma and infiltrating duct carcinoma of the breast. Br J Cancer. 1984; 50: 23-30. PMid: 6331484. http://dx.doi.org/10.1038/bjc.1984.135

[5] Chan A, Morey A, Brown B, et al. A retrospective study investigating the rate of HER2 discordance between primary breast carcinoma and locoregional or metastatic disease. BMC Cancer. 2012; 12: 555. PMid: 23176370. http://dx.doi.org/10.1186/1471-2407-1 2-555

[6] Vincent-Salomon A, Jouve M, Genin P, et al. HER2 status in patients with breast carcinoma is not modified selectively by preoperative chemotherapy and is stable during the metastatic process. Cancer. 2002; 94: 2169-73. PMid: 12001113. http://dx.doi.org/10.10 02/cncr. 10456

Published by Sciedu Press
[7] Gancberg D, Di LA, Cardoso F, et al. Comparison of HER-2 status between primary breast cancer and corresponding distant metastatic sites. Ann Oncol. 2002; 13: 1036-43. PMid: 12176781. http://dx.doi.org/10.1093/annonc/mdf252

[8] Taal BG, Peterse H, Boot H. Clinical presentation, endoscopic features, and treatment of gastric metastases from breast carcinoma Cancer. 2000; 89: 2214-21. http://dx.doi.org/10.1002/109 7-0142 (20001201) 89:11<2214: :AID-CNCR9>3 . 0.CD;2-D

[9] Pestalozzi BC, Zahrieh D, Mallon E, et al. Distinct clinical and prognostic features of infiltrating lobular carcinoma of the breast: combined results of 15 International Breast Cancer Study Group clinical trials. J Clin Oncol. 2008; 26: 3006-14. PMid: 18458044 http://dx.doi.org/10.1200/JC0.2007.14.9336

[10] Pectasides D, Psyrri A, Pliarchopoulou K, et al. Gastric Metastases Originating from Breast Cancer: Report of 8 Cases and Review of the Literature. Anticancer Res. 2009; 29: 4759-63. PMid: 20032432.

[11] Jones GE, Strauss DC, Forshaw MJ, et al. Breast cancer metastasis to the stomach may mimic primary gastric cancer: report of two cases and review of literature. World J Surg Oncol. 2007; 5: 75. PMid: 17620117. http://dx.doi.org/10.1186/1477-7819-5-75

[12] Taal BG, Boot $\mathrm{H}$, van Heerde $\mathrm{P}$, et al. Primary non-Hodgkin lymphoma of the stomach: endoscopic pattern and prognosis in low versus high grade malignancy in relation to the MALT concept. Gut. 1996; 39: 556-61. PMid: 8944565. http://dx.doi.org/10.11 36/gut.39.4.556

[13] Lorimier G, Binelli C, Burtin P, et al. Metastatic gastric cancer arising from breast carcinoma: endoscopic ultrasonographic aspects. 
Endoscopy. 1998; 30: 800-4. PMid: 9932762. http://dx.doi.o $\mathrm{rg} / 10.1055 / \mathrm{s}-2007-1001425$

[14] Hara F, Kiyoto S, Takabatake D, et al. Metastatic Breast Cancer to the Stomach Resembling Early Gastric Cancer. Case Rep Oncol. 2010; 3: 142-7. PMid: 20740187. http://dx.doi.org/10.1159/000 313923

[15] Liu H, Shi J, Wilkerson ML, et al. Immunohistochemical evaluation of GATA 3 expression in tumors and normal tissues: a useful immunomarker for breast and urothelial carcinomas. Am J Clin Pathol. 2012; 138: 57-64. PMid: 22706858. http://dx.doi.org/10.1309/A JCP5UAFMSA9ZQBZ

[16] Fleming TP, Watson MA. Mammaglobin, a breast-specific gene, and its utility as a marker for breast cancer. Ann N Y Acad Sci. 2000; 923: 78-89. PMid: 11193781. http://dx.doi.org/10.1111/j .1749-6632.2000.tb05521.x

[17] Kim DH, Shin N, Kim GH, et al. Mucin expression in gastric cancer: reappraisal of its clinicopathologic and prognostic significance. Arch Pathol Lab Med. 2013; 137: 1047-53. PMid: 23899060. http://dx.doi.org/10.5858/arpa.2012-0193-0A

[18] Gendler SJ, Spicer AP. Epithelial Mucin Genes. 2003.

[19] Lindström LS, Karlsson E, Wilking UM, et al. Clinically used breast cancer markers such as estrogen receptor, progesterone receptor, and human epidermal growth factor receptor 2 are unstable throughout tumor progression. J Clin Oncol. 2012; 30: 2601-8. PMid: 22711854 http://dx.doi.org/10.1200/JC0.2011.37.2482

[20] Aurilio G, Disalvatore D, Pruneri G, et al. A meta-analysis of oestrogen receptor, progesterone receptor and human epidermal growth factor receptor 2 discordance between primary breast cancer and metastases. Eur J Cancer. 2014; 50: 277-89. PMid: 24269135. http://dx.doi.org/10.1016/j.ejca.2013.10.004

[21] Van de VS, Smit VTHBM, Dekker TJA, et al. Discordances in ER, PR and HER2 receptors after neoadjuvant chemotherapy in breast cancer. Cancer Treat Rev. 2011; 37: 422-30. PMid: 21177040.

[22] Yang YF, Liao YY, Li LQ, et al. Changes in ER, PR and HER2 receptors status after neoadjuvant chemotherapy in breast cancer. Pathol Res Pract. 2013; 209: 797-802. PMid: 24183366. http: //dx.doi.org/10.1016/j.prp.2013.08.012

[23] Swain SM, Baselga J, Kim SB, et al. Pertuzumab, Trastuzumab, and Docetaxel in HER2-Positive Metastatic Breast Cancer. N Engl J Med. 2015; 372: 724-34. PMid: 25693012. http://dx.doi.org/10.10 56/NEJMoa1413513

[24] Carney WP. Potential Clinical Utility of Serum HER-2/neu Oncoprotein Concentrations in Patients with Breast Cancer. Clin Chem. 2003; 49: 1579-98. PMid: 14500583. http://dx.doi.org/10.1373/4 9.10.1579

[25] Esteva FJ, Cheli CD, Fritsche H, et al. Clinical utility of serum HER2/neu in monitoring and prediction of progression-free survival in metastatic breast cancer patients treated with trastuzumab-based therapies. Breast Cancer Res. 2005; 7: R436-43. PMid: 15987448 http://dx.doi.org/10.1186/bcr1020

[26] Carney WP, Neumann R, Lipton A, et al. Monitoring the circulating levels of the HER2/neu oncoprotein in breast cancer. Clin Breast Cancer. 2004; 5: 105-16. PMid: 15245613. http://dx.doi.org /10.3816/CBC.2004.n.014 